\title{
Study on Delineation of Irrigation Management Zones Based on Management Zone Analyst Software
}

\author{
Qiuxiang Jiang, Qiang Fu', and Zilong Wang \\ College of Water Conservancy \& Architecture, Northeast Agricultural University, \\ Harbin 150030, Heilongjiang Province, P.R. China \\ fuqiang@neau.edu.cn
}

\begin{abstract}
For more efficient field operation and management of precision irrigation, Management Zone Analyst (MZA) software was used to delineate irrigation management zones. MZA is a simple and fast software for subfield management zone delineation on the basis of fuzzy c-means clustering algorithm. The measured soil physical properties of Chahayang Farm in Heilongjiang Province were taking as data source in the paper. Principal component analysis was firstly used to eliminate the multiple correlations of the data and MZA was then performed to delineate irrigation management zones of the study area. The results indicated that the study area was divided into two irrigation management zones by MZA, and soil physical properties had high uniformity in each subzone and significant difference between subzones which confirmed the partition. The delineation of irrigation management zones based on MZA had high precision and could make up the deficiencies of higher theoretical level and hard mastery of other clustering algorithms. The delineation results based on MZA can provide the basis for decision making of precision irrigation practices.
\end{abstract}

Keywords: irrigation management zones, principal component analysis, MZA, geostatistics.

\section{Introduction}

Management zone is a subzone with similar crop production potential, soil nutrient, water use efficiency and environmental effects caused by similar landscape or soil conditions (Li Yan et al., 2007a). Scientific and rational delineation technique of management zone is the efficient means of conducting variable rate fertilization and irrigation in precision agriculture and has become a hot spot of precision agriculture at home and abroad. Ostergaard et al. (1997) have used the data of soil type, yield, terrain, aerial photograph and farmers' experience etc. as qualitative analysis indexes to delineate management zones. Fleming et al. (2000) have delineated management zones of a certain region by using overlapping method (a qualitative analysis) to superimpose the aerial photograph of bare land and terrain map of the region and

\footnotetext{
* Corresponding author.
} 
integrating the management experiences of farmers. Li Yan et al. (2007b) have taken NDVI, soil salinity and crop yield as data sources and used fuzzy c-means clustering to delineate management zones. Li Xiang et al. (2007) have used fuzzy k-means clustering algorithm to divided the study area into four management zones based on the data sources of two soil nutrients (available phosphorus and available nitrogen). Jiang Qiuxiang et al. (2010) have used the data source of soil moisture and colony clustering algorithm to delineate site-specific irrigation management zones. Wang Zilong et al. (2008) have studied the delineation of soil nutrient management zones by using attribute means clustering based on particle swarm optimization algorithm.

Experiential method and clustering method are the main methods to delineate management zones in the above studies. Experiential method has a low resolving precision for clustering analysis is not performed on the data of delineating management zones. However, clustering method demands that the users have a certain mathematical basis, especially the clustering methods that are too theoretical and have elaborate calculation procedures are hard to be used in productive practices. Management Zone Analyst (MZA) software written by Fridgen et al. (2004) on the basis of fuzzy c-mean clustering algorithm is a simple software. Users just need to input data into the software and will obtain results quickly. Thus, MZA software was conducted in the study to delineate precision irrigation management zones, which can provide a new train of thought for management zone delineation.

\section{Materials and Methods}

\subsection{Site Description and Soil Sampling}

The study was conducted on a dry field of 1ha in the dry cultivation techniques demonstration area of Chahayang Farm, which is in the western semiarid region of Heilongjiang Province. It is located in the cold temperate zone, continental monsoon and semiarid agricultural climate region. Thus study on precision irrigation in the area is significant. A $10 \mathrm{~m} \times 10 \mathrm{~m}$ grid-sampling scheme was performed on the field to collect 300 soil samples from three layers in the topsoil $(0-30 \mathrm{~cm})$ in the autumn of 2006 after crop harvesting. One representative sample was collected at the center of each grid and geo-referenced using a global positioning system (GPS). Four indices, including field moisture capacity (FMC), saturated moisture content (SMC), wilting point (WP) and soil dry bulk density (SDBD), were measured by conventional methods (Soil Physics Research Office, Institute of Soil Science, Chinese Academy of Sciences, 1978) for three layers soil samples in each sampling position, and the means of them was considered as values of the parameters at the location.

\subsection{Management Zone Analyst Software}

For quickly creating management zones and ascertaining the rational number of zones, Fridgen et al. (2004) developed a software program called Management Zone Analyst (MZA) by using Microsoft Visual Basic 6.0. MZA can assist researchers, consultants and producers in creating management zones using quantitative soil, crop and/or site information. MZA calculates descriptive statistics, performs the unsupervised fuzzy 
classification procedure to delineate management zones. The advantages of MZA are that it provides concurrent output for a range of cluster numbers and two performance indices [fuzziness performance index (FPI) and normalized classification entropy (NCE)] to aid in deciding how many clusters are most appropriate for creating management zones, which can help the users obtain management zones simply and quickly (Fridgen et al., 2004).

The fuzziness performance index (FPI) is a measure of the degree of separation between fuzzy c-partitions of data matrix $(X)$ and is defined as:

$$
F P I=1-\frac{c}{(c-1)}\left[1-\sum_{k=1 i=1}^{n} \sum_{i=1}^{c}\left(u_{i k}\right)^{2} / n\right]
$$

where $u_{i k}(1 \leq i \leq c, 1 \leq k \leq n)$ is the membership that the $k$ th sample $\left(x_{k}\right)$ of $X$ belongs to the centroid of cluster $i\left(v_{i}\right)$ of the cluster centroid matrix $(V) ; c$ and $n$ are the number of cluster centroid and the number of observations, respectively.

The NCE models the amount of disorganization of a fuzzy c-partition of X. The classification entropy $(H)$ is defined by the function:

$$
H(U ; c)=-\sum_{k=1 i=1}^{n} \sum_{i k} \log _{a}\left(u_{i k}\right) / n
$$

where logarithmic base $a$ is any positive integer.

Then, the NCE can be expressed as follows:

$$
N C E=H(U ; c) /[1-(c / n)]
$$

The values of FPI and NCE close to 0 mean the small membership sharing and large partition component, indicating the good classification results (Bezdek, 1981). The best number of classification can be obtained when both FPI and NCE have the minimum values at the class. The additional verification is required to determine how many clusters to be used for creating management zones when both performance indices have different number of zoning (Fraisse et al., 2001).

\subsection{Data Processing Procedure}

Soil physical properties being provided with spatial variabilities and heterogeneous spatial distributions is the important prerequisite for delineating site-specified irrigation management zones. Thus, first of all, geostatistical analysis software called GS+ 5.3 was performed to analyze the spatial variability and structure of soil physical properties in the study. Then, the heterogeneities of spatial distributions for all the soil physical properties were judged by their spatial distribution maps drawn in ArcGIS 9.1 by using the kriging interpolation method. Next, for correlations existed among soil physical properties, principal component analysis (PCA) was used to eliminate data correlations and extract comprehensive indexes before delineating management zones. Finally, management zone was delineated in MZA by using the comprehensive indexes as input. 


\section{Results and Discussion}

\subsection{Spatial Variability Structure Analysis}

Analysis results of spatial variability structure for all soil physical properties were listed in Table 1 . The nugget values $\left(\mathrm{C}_{0}\right)$ of all soil physical properties measured in the study were less than their structural variances $(C)$, which indicated that the spatial variability of the soil physical properties was mainly arisen by structural or inartificial factors (such as soil parent material, terrain and climate). The nugget/sill $\left[\mathrm{C}_{0} /\left(\mathrm{C}_{0}+\mathrm{C}\right)\right]$ ratios for all soil physical properties ranged from $20.64 \%$ to $22.92 \%$. The spatial variability of the properties was weak [when $\mathrm{C}_{0} /\left(\mathrm{C}_{0}+\mathrm{C}\right)<25 \%$ ] but close to moderate degree [when $25 \%<\mathrm{C}_{0} /\left(\mathrm{C}_{0}+\mathrm{C}\right)<75 \%$ ]. Fig. 1 showed the spatial distribution maps of the soil properties and all their spatial distributions were heterogeneous. WP had sheet

Table 1. Models and parameters of semivariograms for the regional variables

\begin{tabular}{cccccccc}
\hline $\begin{array}{c}\text { Regional Theoretical Nugget } \\
\text { variable }\end{array}$ & model & $\begin{array}{c}\text { Structural } \\
\text { variance } \\
\left(\mathrm{C}_{0}\right)\end{array}$ & $\begin{array}{c}\text { Sill } \\
(\mathrm{C})\end{array}$ & $\begin{array}{c}\text { Nugget/sill ratio } \\
{\left[\mathrm{C}_{0}+\mathrm{C}\right)}\end{array}$ & $\begin{array}{c}\text { Range } \\
\left.(\mathrm{C}) /\left(\mathrm{C}_{0}+\mathrm{C}\right)\right](\%)\end{array}$ & $\begin{array}{c}\text { Coefficient of } \\
\text { determination }\end{array}$ \\
\hline FMC & Spherical & 0.57 & 2.06 & 2.63 & 21.49 & 23.4 & 0.938 \\
SMC & Spherical & 4.80 & 18.39 & 23.19 & 20.70 & 19.1 & 0.878 \\
WP & Spherical & 0.11 & 0.42 & 0.53 & 20.64 & 94.2 & 0.934 \\
SDBD & Spherical & 0.001 & 0.004 & 0.005 & 22.92 & 19.2 & 0.829 \\
\hline
\end{tabular}
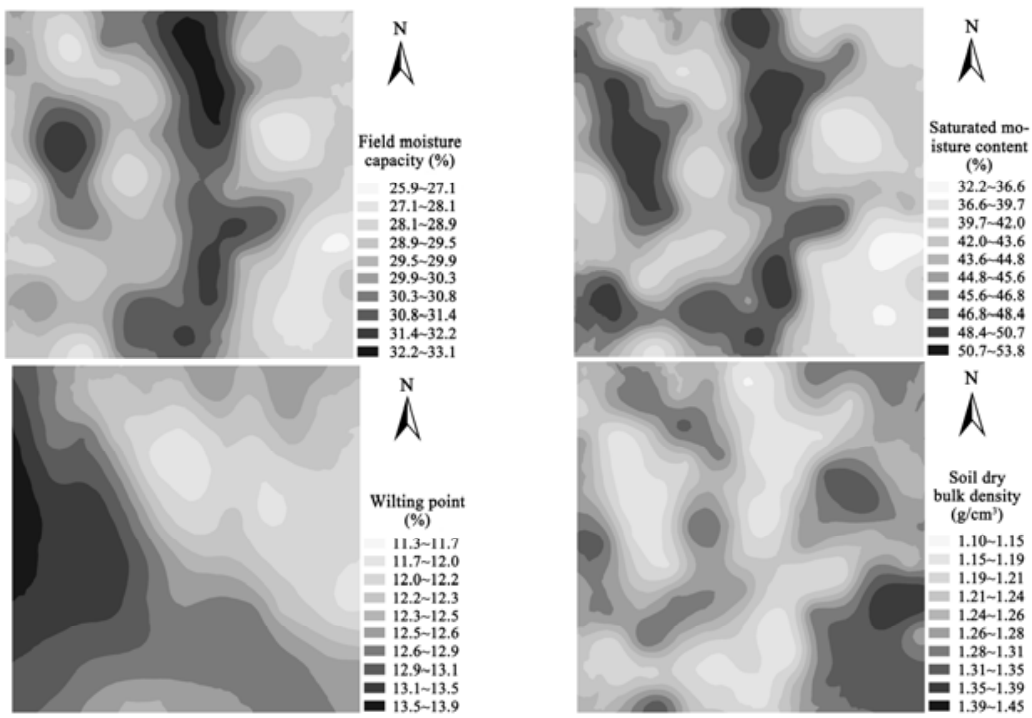

Fig. 1. Spatial distribution maps of soil physical properties 
spatial distribution, while the spatial distributions of FMC, SMC and SDBD were all zonal. The spatial characteristics of all the soil physical properties accorded with the prerequisite of delineating site-specified irrigation management zones. Thus, the four soil properties could be used to delineate management zones.

\subsection{Analyzing Correlation and Extracting Comprehensive Index}

The results of correlation analysis were shown in Table 2 . The correlation coefficient of SDBD and SMC and that of SDBD and FMC was -0.982 and -0.858 , respectively. FMC and SMC also had strong relation with a correlation coefficient of 0.851 . All the properties showed extremely significant correlations $(\mathrm{P}<1 \%)$. Thus, principal component analysis was conducted to eliminate the correlation and extract the comprehensive index of the properties before delineating irrigation management zones, and the results were listed in Table 3 and Table 4.

Table 2. Correlation analysis of soil physical properties

\begin{tabular}{ccccc}
\hline Item & FMC & SMC & WP & SDBD \\
\hline FMC & 1 & & & \\
SMC & $0.851^{*}$ & 1 & & \\
WP & 0.104 & 0.179 & 1 & 1 \\
SDBD & $-0.858^{*}$ & $-0.982^{*}$ & -0.117 & 1 \\
\hline
\end{tabular}

Note: $*$ is $P<0.01$.

Table 3. Eigenvalues and cumulative contribution ratios of principal components

\begin{tabular}{cccc}
\hline $\begin{array}{c}\text { Principal } \\
\text { component }\end{array}$ & Eigenvalue & $\begin{array}{c}\text { Variance contribution ratio } \\
(\%)\end{array}$ & $\begin{array}{c}\text { Cumulative contribution ratio } \\
(\%)\end{array}$ \\
\hline F1 & 2.82426 & 70.61 & 70.61 \\
F2 & 0.973909 & 25.35 & 95.96 \\
F3 & 0.185477 & 3.64 & 99.60 \\
F4 & 0.0163508 & 0.40 & 100 \\
\hline
\end{tabular}

Table 4. Load matrixes of principal components

\begin{tabular}{ccccc}
\hline $\begin{array}{c}\text { Principal } \\
\text { component }\end{array}$ & FMC & $\begin{array}{c}\text { SMC } \\
(\mathrm{X} 1)\end{array}$ & $\begin{array}{c}\text { WP } \\
(\mathrm{X} 2)\end{array}$ & $\begin{array}{c}\text { SDBD } \\
(\mathrm{X} 4)\end{array}$ \\
\hline F1 & -0.9289 & -0.9802 & -0.2114 & 0.9777 \\
F2 & -0.1017 & -0.0255 & 0.9772 & 0.0892 \\
\hline
\end{tabular}

Among the four principal components extracted from original indexes by PCA, the cumulative contribution ratio of F1 and F2 approached 95\%, which illuminated that the information of the four indices could be superseded by F1 and F2 at a precision of $95 \%$.

By calculating the load matrices of F1 and F2, they can be expressed as:

$$
\begin{aligned}
& F 1=-0.9289 X 1-0.9802 X 2-0.2114 X 3+0.9777 X 4 \\
& F 2=-0.1017 X 1-0.0255 X 2+0.9772 X 3+0.0892 X 4
\end{aligned}
$$


The principal component is a comprehensive variable compounded linearly by the original variables. The compounding coefficient suggested the correlation between the original variable and the comprehensive variable. The coefficients of X1, X2 and X4 in the first principal component (F1) were relatively large, indicating that F1 was the comprehensive variable affected jointly by FMC, SMC and SDBD. However, in the second principal component (F2), X3 had a relatively large coefficient suggesting that WP played a decisive role on F2. The two comprehensive variables not only contained the four original indices but also had no correlation between them. Thus, F1 and F2 were used as the clustering variables for delineating irrigation management zones.

\subsection{Delineating Irrigation Management Zones}

Comprehensive variables (F1 and F2) were calculated based on the data of the measured soil physical properties and regarded as the input data of MZA software. The fuzziness performance index (FPI) and normalized classification entropy (NCE) when the clustering number was 2, 3, 4, 5 and 6 respectively were obtained from MZA and shown in Fig. 2. FPI and NCE achieved the smallest values at the same time that the number of management zones was 2, namely, the classification effect was best when the study area was partitioned into 2 irrigation management zones. The irrigation management zones map was obtained from ArcGIS software with the input data of the best classification values and shown in Fig. 3. The spatial distributions of the two subzones were banded and interlaced mutually. And the areas of the two subzones were basically the same with the area of Zone I of $4933 \mathrm{~m}^{2}$ and with the area of Zone II of $5067 \mathrm{~m}^{2}$.

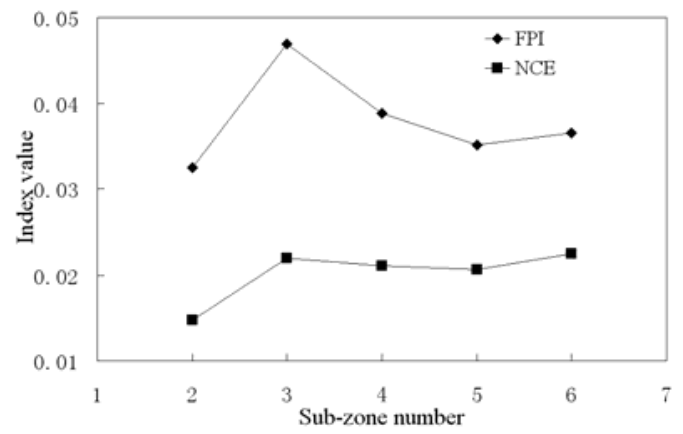

Fig. 2. Changes in two performance indices with increasing number of management zones

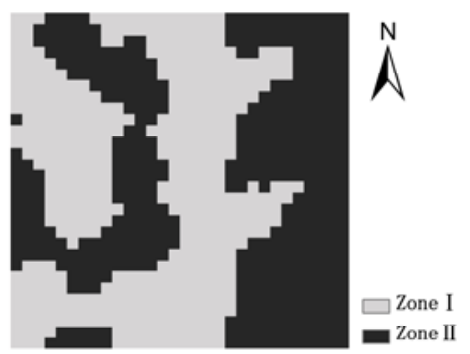

Fig. 3. Optimal precision irrigation management zones for the study area 


\subsection{Effect Assessment of Management Zones Delineation}

To more intuitively characterize the differences in subzone and between subzones, classical statistics and one-way ANOVA were conducted on all the soil physical properties in each subzone and the results were listed in Table 5 and Table 6 . The coefficients of variation of the properties in the two subzones were all smaller than that of the whole study area, which suggesting that the difference in the subzone decreased and the homogeneity increased. The differences between subzones for the properties were extremely significant according to the results from one-way ANOVA. The analysis results indicated that the soil physical properties were relatively homogeneous in each subzone and were obviously heterogeneous between subzones after the study area was partitioned into two irrigation management zones by using PCA method and MZA software. Thus, the delineation of irrigation management zones for the study area was reasonable.

Table 5. Coefficients of variation for soil physical properties in subzones

\begin{tabular}{ccccc}
\hline Subzone & FMC & SMC & WP & SDBD \\
\hline Zone I & 2.61 & 3.64 & 3.33 & 2.32 \\
Zone II & 2.35 & 5.25 & 3.44 & 2.41 \\
Whole area & 3.83 & 7.75 & 3.57 & 4.01 \\
\hline
\end{tabular}

Table 6. Results of one-way ANOVA for soil physical properties among subzones

\begin{tabular}{ccccc}
\hline Variance analysis & FMC & SMC & WP & SDBD \\
\hline $\mathrm{F}$ & 1217.36 & 1827.79 & 38.77 & 1727.78 \\
$\operatorname{Pr}>\mathrm{F}$ & $<0.0001$ & $<0.0001$ & $<0.0001$ & $<0.0001$ \\
$\begin{array}{c}\text { Criterion of } \\
\text { significance }\end{array}$ & Very significant & Very significant & Very significant & Very significant \\
\hline
\end{tabular}

Table 7. Mean values of soil physical properties in each subzone

\begin{tabular}{lccccc}
\hline Subzone & Area $\left(\mathrm{m}^{2}\right)$ & FMC $(\%)$ & SMC $(\%)$ & WP $(\%)$ & SDBD $\left(\mathrm{g} / \mathrm{cm}^{3}\right)$ \\
\hline Zone I & 4933 & 30.61 & 46.69 & 12.68 & 1.207 \\
Zone II & 5067 & 28.88 & 41.13 & 12.50 & 1.288 \\
\hline
\end{tabular}

The mean values of the soil physical properties in each subzone were calculated and listed in Table 7 for the sake of finding out the differences between subzones. The mean values of all soil physical properties except SDBD in Zone I were larger than that in Zone II, which illuminated that Zone I with smaller SDBD had stronger soil carrying capacity and drought-enduring capacity than Zone II. Thus, proper water retention measures were proposed for Zone II.

\section{Conclusions}

According to the spatial variation structure analysis of soil physical properties, all properties had spatial variability and heterogeneous spatial distribution, which satisfied the preconditions of delineating site-specified irrigation management zones. For strong 
correlations among the soil properties, PCA was performed to eliminate the correlations and two principal components were extracted as comprehensive indexes for delineating management zones. The study area was partitioned into two irrigation management zones, and the differences between subzones and the homogeneities in each subzone were all enhanced. Zone II had weaker soil water carrying and droughtenduring capacity than Zone I, so water retention measures were necessary for Zone II.

Using easy-operating MZA software in the study to delineate management zones reduced study requirements of basic theories for operators and overcame the disadvantages of high theoretical level and hard mastery of quantitive analysis. Strong scientificalness, high precision and fast speed are the characteristics of this method which provides a simple and quick way for the delineation of site-specified irrigation management zones.

\section{Acknowledgements}

Funding for this research was provided by Key Projects in the National Science \& Technology Pillar Program during the Eleventh Five-Year Plan Period of China (No.2009BADB3B0205), Scientific and Technological Project of Heilongjiang Province of China (No.GB06B106-7), Specialized Research Fund for the Doctoral Program of Higher Education of China (No.20092325110014), New Century Excellent Talents in University of Heilongjiang Province of China (No.1155-NCET004) and Postdoctoral Science Foundation of Heilongjiang Province of China (No.LBH-Q07019).

\section{References}

1. Li, Y., Shi, Z., Wu, C., et al.: Definition of management zones based on fuzzy clustering analysis in coastal saline land. Scientia Agricultura Sinica 40(1), 114-122 (2007)

2. Ostergaard, H.G.S.: Agronomic consequences of variable N fertilization. In: Stafford, J.V. (ed.) Proceeding of the 1st European Conference on Precision Agriculture, pp. 315-320. BIOS Scientific Publishers, Oxford (1997)

3. Fleming, K.L., Westfall, D.G., Wiens, D.W., et al.: Evaluating farmer developed management zone maps for variable rate fertilizer application. Precision Agriculture 2, 201-205 (2000)

4. Li, Y., Shi, Z., Wu, C., et al.: Classification of management zones for precision farming in saline soil based on multidata sources to characterize spatial variability of soil properties. Transactions of the CSAE 23(8), 84-89 (2007)

5. Li, X., Pan, Y., Ma, J., et al.: Soil Nutrients-based zoning for management of precision agriculture. Acta Pedologica Sinica 44(1), 14-19 (2007)

6. Jiang, Q., Fu, Q., Wang, Z.: Application of improved ant colony clustering method in the delineation of site-specified irrigation management zones. Transactions of the CSAE 26(2), 37-42 (2010)

7. Wang, Z., Fu, Q., Jiang, Q.: Soil nutrient management zones based on particle swarm optimization algorithm. Transactions of the CSAE 24(10), 80-84 (2008)

8. Fridgen, J.J., Kitchen, N.R., Sudduth, K.A.: Management zone analyst (MZA): software for subfield management zone delineation. Agronomy Journal 96, 100-108 (2004) 
9. Soil Physics Research Office, Institute of Soil Science, Chinese Academy of Sciences. In: Determination of Soil Physical Properties, pp. 99-121. Science Press, Beijing (1978)

10. Bezdek, J.C.: Pattern Recognition with Fuzzy Objective Function Algorithms. Plenum Press, New York (1981)

11. Fraisse, C.W., Sudduth, K.A., Kitchen, N.R.: Delineation of site-specific management zones by unsupervised classification of topographic attributes and soil electrical conductivity. Transactions of the ASAE 44(1), 155-166 (2001) 